Reviews

knowledge of the original texts. For example, the idea of nature as mechanistic, so central to his interpretation of Hobbes, is never fully explained by Meyer.

For readers who are well acquainted with the theories and writings being analyzed, Meyer's book offers a thoughtful look at environmentalism, philosophy, politics and discourse. The extensive bibliography contains a wide range of works from the diverse areas of environmentalist theory, cultural ecology, and philosophy- useful to those interested in studying the history and development of these subjects. Some readers may be disappointed that the last chapter is so short. After following Meyer's carefully developed argument for "political nature" we are given only the briefest opportunity to see what such an analysis might look like when applied to contemporary issues. The three cases altogether are given only eight pages. If we accept Meyer's thesis that a deeper understanding of environmental conflicts requires an examination of the conceptions of politics and nature, then surely more than a couple of pages is needed for an adequate treatment, especially if it is to serve as an example of his approach.

In sum, Meyer's concept of political nature is a call to keep open the debates about how to define key concepts for environmental issues while giving attention to the fact that multiple interpretations exist, and striving to understand the ways that some of these are more privileged than others in a given socio-political context. Meyer points to experiences of place as the heart of political nature, reminding us that decisions about how we interact with our environments are inherently political and that political decisions are also embedded in nature and our conceptions of it. This book makes a valuable contribution to the political ecology literature while offering relevant theoretical and analytical approaches to the disciplines of political science, anthropology, philosophy and environmental studies.

\title{
Political Ecology and the Role of Water: Environment, Society and Economy in Northern Yemen, by Lichtenthaler, Gerhard (2003). Aldershot: Ashgate.
}

\section{Reviewed by Charles Schmitz, Assistant Professor, Department of Geography and} Environmental Planning, Twonson University.

cschmitz@towson.edu

Intimate local knowledge can be a powerful yardstick of grand theory and the efficacy of broad policy prescriptions. Lichtenthaler's rich knowledge and long association with the region of his field study, the Sa'dah basin in northern Yemen, allows him to easily see through many of the accepted truths of water resource management in the developing world. But having deconstructed conventional wisdom, Lichtenthaler is left a little puzzled and clearly concerned about Sa'dah's future. He leaves us with just a prayer and poem for the future.

In Political Ecology and the Role of Water, Lichtenthaler searches for solutions to what seems a hopeless situation. Groundwater in the Sa'dah basin of northern Yemen is dropping precipitously and there is no plausible solution in sight. Conventional wisdom offers little recourse, or worse, contributes to the problem. Privatization of water resources, Garret Hardin's solution to his 'tragedy of the commons,' was adopted indigenously when new pumping technology offered access to abundant groundwater. Now, however, what is rational for the individual actor actually inhibits collective regulation of ground water abstraction. Worse, privatization of water is now contributing to the marginalization of smaller farmers who are unable to keep pace with the costs of constantly deeper drilling for the falling water table. Similarly, the international development agencies' political correct "decentralized and locally designed" projects that are "culturally sensitive" to local tradition are not very helpful in Sa'dah because local society itself is the source of much of the problem. Even the modernizing state cannot provide the social framework necessary for an effective adaptive strategy because state behavior also contributes significantly to the current problem. And finally, socio-economic development that would transfer water to more efficient alternative uses in industries is a remote possibility in Sa'dah. Left with little else, Lichtanthaler hopes that lessons are being learned and that local tribal society will generate institutional means to collectively manage water in a socially sustainable manner, these latter recorded and transmitted through popular poetry and Islamic reinterpretation. Recent news from Sa'dah is not good, however; local society was ripped asunder by three months of armed conflict during the summer of 2004 between rebels and government forces. 
In the first chapter Lichtenthaler introduces the study by focusing our attention on the field of political ecology and the Sa'dah basin's "politicized" environment. Political ecology reinserts politics into what is often a socially sanitized technical field, such as in the policy prescriptions of the World Bank (whose charter forbids it from discussing politics). Water management is not simply a technical question governing the physics of natural resources or even a straightforward economic question of the rational and efficient allocation of resources between uses and between users, but rather water management, as all resource management, is inseparable from questions of power and politics. Thus Lichtenthaler in Sa'dah "investigates the extent to which environmental degradation, and especially the unsustainable mining of the Sa'dah basin's groundwater resources......can be explained as the outcome of unequal power relations, political interests, and the changing ability of actors to control or resist other actors" (p.2). Sa'dah's environment is highly "politicized" says Lichtenstaler and following Bryant and Bailey (Bryant and Bailey 1997), "power is at the heart of this politicized environment." Lichtenthaler attributes much of the problem in Sa'dah to this "politicized" environment, but Lichtenthaler does not distinguish here between a "normal" political ecology in which power relations are reflected in resource policy and management practices and the "highly politicized environment" of Sa'dah. What distinguishes Sa'dah is that, in local parlance, "the powerful eat the weak," a fact that Lichtenthaler seems to attribute to tribal social relations and religious fatalism (p.23), but is actually a widespread reality in tribal and non-tribal, religious and secular Yemen. Sa'dah and Yemen's "highly politicized environment" is perhaps a result of rapid social transition, but it is a transition in which short term political interests brazenly trump social development. It is the prominence of raw power unmitigated by institutions charged with long term social sustainability that Lichtenthaler calls Sa'dah's "highly politicized environment," and that leaves many investigators inside and outside of Yemen shaking their heads in disbelief.

In the second chapter Lichtenthaler builds the conceptual framework (as $\mathrm{PhD}$ students are instructed to do) around a collection of concepts loosely glued together to explain Sa'dah basin's predicament: Turton and Ohlsson's concept of adaptive capacity (Turton and Ohlsson 1999), Allan and Karshenas' (Allan and Karshenas 1996) link between socio-economic development and natural resource reconstruction, virtual water, food security and finally, resource capture. In the best of worlds, initial natural resource extraction leads to depletion or "first order" scarcity but then both increased socio-economic development and society's adaptive capacity allow the establishment of forms of resource extraction and use that are sustainable. Socio-economic development enables society to develop more efficient uses of resources through an increase in technical capacity and/or a reallocation of resources to alternate, more efficient uses such as in industry, for example. But these efficiencies are only achieved if society possesses the social means to effect such changes, or "adaptive capacity." Lichtenthaler argues that society in the Sa'dah basin lacks this capacity and thus suffers not only from the "first order" scarcity of diminishing water supplies but also the more serious "second order" scarcity of social means to address environmental stress. The difficulty is that in the "politicized environment" of Sa'dah powerful local actors, tribal sheikhs, are subsidized by the Yemeni or Saudi states and therefore they have no incentive to introduce economic efficiencies. Incentives are further distorted by local social premiums placed on particularly inefficient citrus crops. A further and perhaps more serious difficulty is what Lichtenthaler describes as "resource capture" in which these same "powerful actors and/or social groups seek to gain possession and control over natural resources" (p.20). Resource capture "destroys the essential elements needed for co-operation, willingness, trust and legitimacy" and "undermines..... community's adaptive capacity" (p.20). Thus the Sa'dah case confirms that the cause of environmental degradation is not a Malthusian nightmare or common property rights but rather, as political ecologists claim, the workings of politics on patterns of natural resource use.

Chapter three is a detailed examination of the field site in which we get to know the physical and human characteristics of the Sa'dah basin. We learn first that the basin is an arid region whose topography and geological structure favor groundwater recharge over surface runoff. Prior to the development of groundwater resources in the 1970's most of the basin depended upon grazing and spate irrigation, small agricultural plots strategically situated to capture what little runoff was available. Social relations recognized the rights of those small agricultural plots to large catchment areas and thus became a barrier to the development of groundwater when deep drilling technology became available. Surface water runoff to "downstream" plots would be blocked by the development of lands using groundwater. But a key ruling by a religious scholar 
Reviews

and judge allowed a solution to compensate "downstream" plots with grazing land and thereby provide the legal framework by which groundwater exploitation exploded in the 1970s and 1980s. In chapter three we also learn of the complex tribal relations that govern the Sa'dah basin, particularly the central divide between Hashid and Bakil, Hashid more closely aligned with the state and Bakil less so, and that Bakili tribes predominate in the basin. We also learn of the changing political fortunes of tribal groups in Sa'dah, principally the decline of those that fought for the royalists and retention of the Imam and the rise of those that supported the establishment of the republic between 1962 and 1970. From this we conclude that tribal society is fractured and divided and that tensions are exacerbated when tribal divisions overlap disputes over the control of water resources such as runoff for spate irrigation. Finally we meet key social groups and actors in the region, principally tribal sheiks and merchants. What is significant in their stories is the use of power to acquire land and water and the fact that local power is often closely related to relationship with the Yemeni or the Saudi state. "Whereas the tribal shaykh's ability to mediate and solve conflicts used to rest primarily on his social standing and on his knowledge of customary law, his political influence and power at the national level now increasingly determine the outcome of such conflicts" (p.74).

In chapter four we find the factors driving the tremendous expansion of groundwater use in the 1970s and 1980s. These were first the explosion of migration to Saudi Arabia when the oil boom there created vast employment opportunities and then the resulting inflow of worker remittances along with technical expertise developed in Saudi Arabia. Then ground water development expanded when it was realized that tribal tensions were lessened when individuals could control their own groundwater resources as opposed to relying upon the water flowing over the land of others, a measure of autonomy prized in tribal society. Groundwater development was also spurred by fears of various land grabs by either powerful sheikhs within the valley, rival tribal groups, or the Yemeni government itself. Groundwater development established rights to property that were more difficult to contest than the undeveloped "white" land used for grazing. Yemeni trade policy in the form of import bans on citrus fruit also stimulated development of water intense citrus groves. The Yemeni government sought to stimulate higher value added agriculture through an import substitution measure banning imports of fruit from Saudi Arabia. This spurred citrus development and increased water demand.

Chapter five surveys the socio-economic factors that shape farmers' choice of crops in Sa'dah. Here Lichtenthaler argues that cultural and sociological factors are important determinants of crop choice and economic factors alone cannot explain crop choices and water usage. First, Yemen's pervasive social insecurity favors autonomy and self-sufficiency, values also favored by tribal mores. Hence, wheat is often grown when purely economic factors might favor importation of wheat. Similarly, local preferences for livestock production push farmers to cultivate fodder crops such as alfalfa and sorghum. Saudi Arabian demand for meat and the local tradition of sacrificing an animal on holidays and special occasions drives up prices for local livestock. Yemeni trade policy also favors water consuming fruit trees. Import restrictions and subsidies to powerful local sheikhs favor citrus and other cash crop production. Alone, local production of fruit trees may not be detrimental, but high rates of evapotranspiration in a water deficit region commonly leads to the accumulation of salt deposits in soils. Farmers therefore favor flood basin irrigation that washes away salts over more water efficient methods such as drip irrigation. Lichtenthaler argues here in the tradition of cognitive geography that human behavior is based upon environmental perception and that cultural, political and social perceptions "make and unmake a water security issue" (p. 103).

Finally chapter six argues through a series of case examples that while individual farmers are innovative and open to new methods to reduce water demand and use water more effectively, social logic inhibits collective solutions to the over-abstraction of water. What Lichtenthaler calls "resource capture" or the accumulation of resources by some at the expense of others creates an atmosphere of mistrust that inhibits collective solutions. Tribal frictions already present in Yemeni society are exacerbated by the accumulation of land by politically connected few at the expense of common tribesmen who do not have the means to drill deeper to chase the falling water table. "The problem is that many of those representing the government, and those associated with it, own large farms themselves, which in turn reduces their credibility" (p. 219). The ability of the modern state to enforce a socially stable regulatory regime is thereby reduced.

The final short chapter summarized the arguments made in previous chapters and quickly concludes with the contradictory claim that "...while there is little evidence of any form of 
sustainable development the Sa'dah study does reveal potential to foster adaptive capacity" (p. 225) Rather that accept the strong evidence presented in the case study that a 'second order' scarcity of social adaptive capacity exists in Sa'dah, Lichtenthaler relies upon a prayer and poem for hope in Sa'dah. Tribal communities are beginning to realize that the "sea" is not limitless and they are engaging in collective management strategies that might possibly be communicated to other communities through poems. This in spite of plenty of contrary evidence presented in chapters two, three and six that local tribal society is rife with tensions that prevent any such collective strategy. The revival of Zaydi scholarship gives Lichtenthaler a prayer of hope that new interpretations of Islam might foster collective social mores and institutions to manage water demand and abstraction. However, Zaydi scholarship, or more precisely the politics of the Zaydi revival exploded in Sa'dah in the summer of 2004, dashing Lichtenthaler's hope that a prayer might save Sa'dah's water. Government troops battled for more than three months to destroy the military capabilities of one particular Zaydi leader, al-Huthi, with very heavy casualties inflicted on both sides.

The politics of the al-Huthi rebellion point to a difficulty in Lichtenthaler's argument. The state, says the author, is perceived as corrupt both because of its relationship with the powerful in Sa'dah's local society and because of the general perception throughout Yemen that government officials look to further their own personal interests rather than any collective good. But as the author points out, the division between local society and the state has blurred. Local sheikhs depend now upon their relations with the state elite or positions in the state military for their source of authority rather than on their ability to effectively mediate local disputes as in the past. The state leadership, in turn, uses divisions in local society, particularly in tribal areas, to its advantage. al-Huthi is a good example. In the complicated politics of Yemen, al-Huthi was used by the president as a Zaidi counterforce to the president's enemies in the Zaidi political party, Hizb al-Haq. Hizb al-Haq had supported the opposition to the president prior to the civil war in 1994. After the war al-Huthi became a member of parliament and was given state resources to bolster his position in local society. However, when al-Huthi's Zaidi revival developed into a powerful political and military force, the national leadership decided it was time to weaken alHuthi. al-Huthi's public image suddenly flip flopped from ally to a terrorist outpost of the Iranian

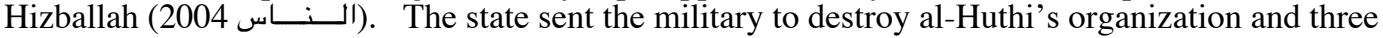
months of pitched war ensued. Thus if local society and the state are inextricably intertwined then water resource management will only be effective when coordinated both on the national and on the local scales. The local and the national cannot be easily separated and currently both contribute to the atmosphere of insecurity and distrust that Lichtenthaler cites as a major roadblock to effective water resource management. Perhaps the author's intimate knowledge of local society has led him to privilege the local over the wider geographic scale of the national state, as local tribal actors tend to do in Yemen.

Political Ecology and the Role of Water is an interesting case study that raises insightful questions about conventional wisdom in the political ecology of resource management. Graduate students and researchers in the field of water resource management will find Lichtenthaler's PhD thesis stimulating reading, though readers may need some background reading in the general history and politics of Yemen in order to appreciate the nuances of the case study.

\section{References Cited}

Allan, J. A. and M. Karshenas

1996. Managing environmental capital: thecase of water in Israel, Jordan, the West Bank and Gaza, 1947 to 1995. Water, peace and the Middle East: negotiating resources in the Jordan Basin. J. A. Allan and J. H. Court. London, I.B. Tauris Publishers.

Bryant, R. L. and S. Bailey

1997. Third World Political Ecology. London, Routledge.

Turton, A. R. and L. Ohlsson

1999. Water scarcity and social adaptive capacity: towards an understanding of the social dynamics of managing water scarcity in development countries. The 9th Stockholm Water Symposium, Stockholm.

. الناس (2004). تمرد الحوثي من أول طلقة. وحتى اخر وساطة! الناس. صنعاء. 206: 4-5. 